\title{
Conductivity and viscosity of dilute solntions of lithium nitrate and cadmium iodide in binary and ternary mixtures of acetone with methyl alcohol, ethyl alcohol and water.
}

By

Harry C. Jones and Edward G. Mahin.

(Ninth Communication)

(With 16 figures in the text.)

The work of Jones with Lindsay ${ }^{1}$, ( Carroll'2), Bingham ${ }^{8}$ ), Mc Master $r^{4}$ ) and Veazey ${ }^{5}$ ), bearing upon the relations existing between conductivity and riscosity of solutions of electrolytes in mixed solvents, has shown that, with a large number of compounds, in binary mixtures of methyl alcohol, ethyl alcohol, acetone and water, the curres representing fluidity (the reciprocal of viscosity) and molecular conductivity have approximately the same form, whether the curves correspond with the rule of mixtures, or pass through maxima or minima as the composition of the solvent mixture is changed. The investigations had to do with about twelve different electrolytes, and measurements were made at $0^{\circ}$ and $25^{\circ}$.

The relations existing between conductivity and viscosity have been the subjects of investigation by many others.

G. Wiedemann ${ }^{6}$ ) showed that the conductivity of copper sulphate in water varies inversely as the coefficient of viscosity, and directly as the concentration.

Stephan ${ }^{7}$ ) expressed his view that each ion of a dissolved electrolyte carries with it an atmosphere of the solvent molecules, so that the

1) Amer. Chem. Journ. 28, 329 (1902); Zeitschr. f. physik. Chemie 56, 129 (1906).

9) Amer. Chem. Journ. 32, 521 (1904); Zeitschr. f. physik. Chemie 56, 129 (1906).

s) Amer. Chem. Journ. 34, 481 (1905); Zeitschr. f. physik. Chemie 57, 193 (1907).

4) Amer. Chem. Journ. 36, 325 (1906); Zeitschr. f. physik. Chemie 57, 257 (1907).

5) Zeitschr. f. physik. Chemie 61, 641 (1908); 62, 44 (1908).

6) Pogg. Ann. 99, 229 (1856).

7) Wied. Ann. 17, 673 (1882). 
resistance to the movement of the ion during the passage of an electric current is, in each case, due to friction of solrent molecules with each other. He concluded that, in alcohol-water mixtures, the conductivity at great dilutions is to be obtained by multiplication of the conductivity in water by a factor which depends only upon the percentage of alcohol, and not upon the nature of the electrolyte; also that molecular conductivity is proportional to fluidity until the proportion of a)cohol becomes greater than about 50 per cent., when the conductivity is less than would be expected.

Grossmann ${ }^{1}$ ) concluded that the product of the molecular conductivity of a given electrolyte with the viscosity of its solutions, is constant and is independent of temperature.

Arrhenius ${ }^{2}$ ) noted the dependence of conductivity upon fluidity, but showed that the nature of the electrolyte must also condition the conductivity in dilute solutions, since otherwise all completely dissociated electrolytes would have the same molecular conductivity in a given solvent.

Vollmer ${ }^{3}$ ) showed that, with a large number of electrolytes, the temperature coefficients of conductivity and of fluidity are identical.

Cohen ${ }^{4}$ ) studied conductivities in mixtures of water and alcohol, and decided that, for a given electrolyte in a given solvent mixture, the molecular conductivity bears a constant ratio to that for the same concentration of the electrolyte in water; the constant being independent of the concentration. This holds also for molecular conductivity at infinite dilution. This conclusion is similar to that reached by Stephan.

Sutherland ${ }^{5}$ ) stated that the degree of dissociation of a dissolved electrolyte is related to both conductivity and viscosity, thus:

$$
\alpha_{v}=\frac{\mu_{v}}{\mu_{\infty}} \cdot \frac{\eta}{\eta_{\infty}} .
$$

Walden ${ }^{6}$ ) determined the viscosity and maximum molecular conductivity of tetraethyl ammonium iodide in water, as well as in about thirty different organic solvents, and showed that, at both $0^{\circ}$ and $25^{\circ}$, the product of viscosity coefficient and maximum molecular conductivity is constant, and that the value of the constant is the same for

1) Wied. Ann. 18, 119 (1883).

2) Zeitschr. f. physik. Chemie 9, 487 (1892).

3ied. Ann. 52, 328 (1894).

4) Zeitschr. f. physik. Chemie 25, 1 (1898).

s) Phil. Mag. [6] 3, 167 (1902).

๑) Zeitschr. f. physik. Chemie 55, 207 (1906). 
both temperatures and for all of the solrents examined, with the exceptions of water and glycol. The value for water was found to be 1.00, that for glycol 1.32 and the mean for all of the other solvents examined 0.700. He remarked that water and glycol seem to stand in distinct classes, as is the case with regard to many other properties. Having this relation in mind, he thought it possible to calculate the maximum molecular conductivity from the known constant and the viscosity coefficient. In the cases studied by $\mathrm{W}$ alden, he found the temperature coefficients of conductivity and of fluidity to be the same.

Arndt ${ }^{1}$ ) referred to the work of others upon this subject and stated that all of the results pointed to the rule that conductivity and viscosity vary inversely. He worked with fused mixtures of sodium metaphosphate and boron trioxide, and found this rule to hold abore $900^{\circ}$.

In the work of Jones with Bingham ${ }^{2}$ ) and with McMaster ${ }^{3}$, certain exceptions to this general relation were found. Lithium bromide, lithium nitrate, cobalt chloride and calcium nitrate, in all solvent mixtures containing acetone as one of the components, gave molecular conductivity curves which differed from the fluidity curves in a striking manner. The conductivity values for pure acetone, and for those solvent mixtures containing a large proportion of acetone, were abnormally low, - so much so that when curves were drawn to represent, respectively, molecular conductivity and fluidity, for changing composition of the solvent mixtures, in some cases maxima appeared in the molecular conductivity curves for those solutions whose fluidity curves showed minima. Further examination of the conductivities in acetone showed that, instead of conforming with Ostwald's, or any other known dilution law, they first increased rery slowly with dilution, and later quite rapidly.

Although these exceptions were overlooked by Arndt in his discussion, they seemed to us to be sufficient to destroy the force of any proposed law which correlates conductivity and viscosity, unless some explanation could be found for the anomalous behavior of solutions of these salts in acetone. This investigation was undertaken in order, if possible, to find the explanation. If, in general, solvents having a small viscosity coefficient should gire solutions of high molecular conductivity with electrolytes which are largely dissociated in them, it is evident that solutions in acetone should exhibit much higher conductivity than solutions in ethyl alcohol, methyl alcohol or water, since the viscosity

1) Z. f. Elektroch. 13, 809 (1907).

\%) Loc. cit.

s) Loc. cit. 
coefficient of acetone is much smaller than that of any of the other three solvents. The fact that the above named salts show abnormally low conductivities in acetone, thus points to the probability of a relatively small ionic concentration. If we consider first the way in which the conductivities increase with increasing dilution, it will be noticed that the first slow increase in molecular conductivity suggests the case of a dilute solution of a nearly completely dissociated salt, while the later rapid increase is what would occur if more of the salt were continually added. This is what might be expected if the salt in the more concentrated solutions were associated to a greater or less extent. This would result in a small initial concentration of single molecules, which, existing in equilibrium with the ionized portion, might themselves obey, at least approximately, one of the dilution laws. Association would become less as more of the solvent were added, resulting in an increase in the number of single molecules, and, subsequently, of ions in the solution.

In 1902 Jones $^{1}$ ) showed that certain salts have abnormally high molecular weights in acetone solutions, although the same solutions conduct the electric current to a considerable extent. He pointed out the fact that this is not inconsistent with Arrhenius' theory of electrolytic dissociation, since it is quite conceivable that association and dissociation mas occur in the same solution. It may be remarked that this is known to be the case, for instance, with many homogeneous liquids, such as water. The salts examined by Jones and found to have molecular weights above the normal were cadmium iodide and ammonium sulphocyanate, both of which Dutoit and Friderich ${ }^{2}$ ) had previously described as having normal molecular weights in acetone. If the above noted abnormal conductivities are to be explained by assuming association of the electrolyte, it should be possible, by attaining sufficiently great dilution, to break down these associated molecules into single molecules, and, subsequently, into ions; in which case the molecular conductivity might reach a value in accord with the rule which has been established in practically all other cases which have been tested, namely, that molecular conductivity is inversely proportional to viscosity. The curves representing molecular conductivity and fluidity, respectively, would then assume similar forms, minima in the one corresponding to minima in the other, etc.

1) Amer. Chem. Journ. 27, 16 (1902).

1) Bull. Soc. Chim. [3] 19, 334 (1898). 
An effort has been made to determine the conductivities of the solutions in question at high dilutions, approaching the region of complete dissociation. We can, at present, see no reason why there should be any constant relation between molecular conductivity and viscosity in different solvents, until this point is reached, bearing in mind the widely differing degrees of dissociation existing in solutions of the same concentration in different solvents. In very dilute solutions the difference between the viscosity of the solution and that of the solvent is generally much less than the experimental error, hence we have directly compared our values for the conductivity of the solution with those for the viscosity of the solvent.

The questions for which we have sought the answer are, then, the following:

1. Will those salts that have, at ordinary concentrations, abnormally low values for molecular conductivity possess, when completely dissociated, values which are inversely proportional to the coefficient of viscosity?

2. If so, is the product of molecular conductivity and viscosity constant for mixed solrents and at different temperatures?

3 . Is the value of the constant the same for different electrolytes?

4. Are the abnormal conductivities in acetone and mixtures of acetone with other solvents due to association of the salt?

\section{Exporimental}

The determination of conductivity in very dilute solutions is attended with considerable difficulty. Dutoit and Levier $\mathbf{r}^{1}$ ), and Du toit2), commenting upon the lack of agreement between conductivity values in acetone, as obtained by different investigators, attributed the differences chiefly to the use of platinized electrodes, to the action of light, and to the use of impure solvents. $C o h e n^{3}$ ) had already noticed that electrodes which are coated with platinum black cause changes in the solutions, resulting in fictitious conductivity values; and he supposed this to be due to catalytic action of the platinum black. Dutoit and Levier also showed that such electrodes gave rise to errors, through adsorption of the dissolved substance. They also observed that the action of light upon acetone solutions causes a decrease in the conductivity;

1) Journ. Chim. Phys. 3, 435 (1905).

) Z. f. Elektroch. 12, 642 (1906).

s) Loc. cit. 
this change being reversed if the solution is subsequently placed in the dark.

In working with very dilute solutions it becomes necessary, either to make comparatively large amounts of each solution by direct weighing of the electrolyte, or to obtain the highly dilute solution by successire additions of solvent to the more concentrated solutions. The first method becomes impracticable when using solvents which are relatively difficult to prepare in the pure state. The second method introduces the error due to the large number of volume measurements which are necessarily made. We have, however, followed the latter method, making each solution from the one next higher in concentration.

\section{Apparatus.}

In making conductivity measurements Kohlrausch's method was used, the Wheatstone bridge, induction coil, resistance coils and telephone being made by Leeds and Company, of Philadelphia. The resistance coils were guaranteed to be accurate to within 0.04 percent. For high resistances, two sets of coils were placed in series, giving a total available resistance of 42000 ohms. The bridge wire was calibrated by the method of Strouhal and Barusi). For compensating the electrostatic capacity of the conductivity cells when measuring high resistances, a condenser was used, consisting of two brass plates, sliding over each other and separated by a thin sheet of paraffined paper. The conductivity cells were those described by Jones and Bingham ${ }^{2}$ ), and the resistance capacity was determined by the use of 0.02 normal and 0.002 normal potassium chloride solutions, 129.7 , the ralue giren by Ostwald ${ }^{3}$ ), being taken as the molecular conductivity of the 0.02 normal solution. The electrodes were platinized before using, by electrolysis of a dilute solution of platinum chloride in the cell, after which they were heated in the flame of a blast-lamp until whitened. After using a given solution, the cell was thoroughly washed out and allowed to stand filled with distilled water for at least a day; it was then dried by means of alcohol. We satisfied ourselves, by repeated tests, that this method of drying did not produce acid on the electrodes. Measurements were made at $0^{\circ}$ and $25^{\circ}$. The thermometers were graduated in $0.2^{\circ}$ intervals and were compared with a thermometer that was certified by the Reichsanstalt.

1) Wied. Ann. 10, 326 (1880).

9) Amer. Chem. Journ. 34, 493 (1905).

s) Lehrbuch, 2. Aufl., S. 732. 
Viscosity measurements were made by means of a modified form of the Ostwald viscometer $\left.{ }^{1}\right)$. The modification has been described by Jones and Veazey ${ }^{2}$ ). Viscosity was calculated from the formula:

$$
\eta=\eta_{0} \cdot \frac{S T}{S_{0} T_{0}}
$$

in which $\eta$ is the viscosity coefficient for the fluid in question, $\eta_{0}$ is the viscosity coefficient for water at the temperature at which the experiment is being carried out, $S$ is the specific gravity of the solvent or solution, $T$ is the time of flow of the solvent or solution, $S_{0}$ is the specific gravity of water at the given temperature, and $T_{0}$ is the time of flow for water. Fluidity was calculated from the formula:

$$
\text { Fluidity }=\Phi=\frac{1}{\eta} \text {. }
$$

The viscosity coefficients for water which were used in the calculations, are those taken from the researches of Thorpe and Roger ${ }^{3}$ ). Specific gravities were determined by the use of the picnometer described by Jones and Veazey. The viscometers and picnometers were made for us by Eimer and Amend of New York.

Burettes and graduated flasks were calibrated by direct meighing of distilled water, on the basis of the true liter, and corrected to use at $20^{\circ}$. Pipettes were not used in any part of the work.

\section{Solvents.}

Water was purified by the method of Jones and Mackay), ordinary distilled water being twice redistilled from chromic acid and once from barium hydroxide. The stills and bottles were protected from the entrance of carbon dioxide by a tube of soda lime. The average specific conductivity of the purified water was $1.2 \times 10^{-6}$ at $0^{0}$.

Methyl alcohol was prepared by boiling over lime and subsequent distillation into a bottle containing fresh lime, where it was allowed to stand for several weeks. It was redistilled immediately before using, and its average specific conductivity was $1 \times 10^{-6}$ at $0^{0}$.

Ethyl alcohol was prepared in the same manner as methyl alcohol. The average specific conductivity at $0^{0}$ was $5 \times 10^{-7}$.

Acetone was allowed to stand for a month or more over fused

1) Physik.-chemische Messungen, 2. Aufl. S. 259.

\#) Zeitschr. f. physik. Chemie 61, 641 (1908).

s) Phil. Trans. 185 (A), 307 (1894).

๑) Zeitschr. f. physik. Chemie 22, 237 (1897). 
calcium chloride, and was distilled immediately before using. Our experience with acetone was quite different from that of Dutoit ${ }^{1}$ ), in that we found that either acetone or solutions in acetone increased in conductivity very decidedly when exposed to sunlight or even fairly bright diffused light. After distillation, therefore, the acetone was kept in the dark except when being used. It is believed that any error due to impurities in the acetone has been small in most cases, since acetone was obtained having a specific conductivity as low as $0.57 \times 10^{-7}$ reciprocal Siemens units at $0^{\circ}$, and $0.75 \times 10^{-7}$ at $25^{\circ}$. Dutoit and Levier stated that $B \theta^{2} z^{2}$ ) obtained acetone having a specific conductivity of $0.23 \times 10^{-7}$ reciprocal Siemens units at $18^{\circ}$, this being the lowest of which we have found any record.

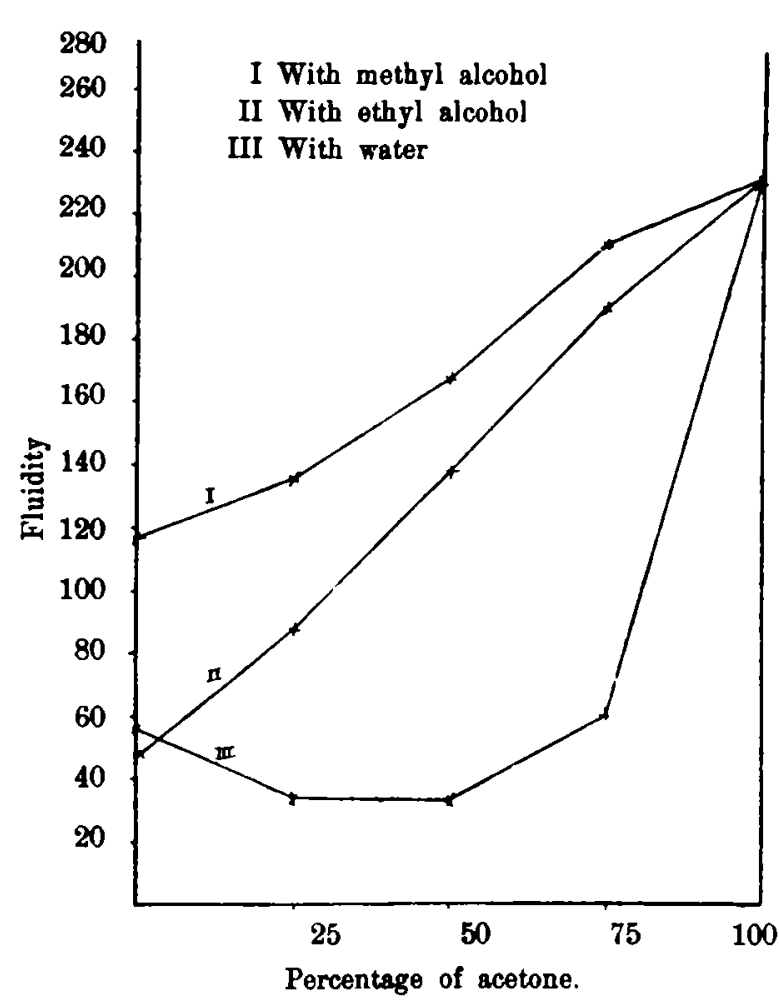

Fig. 1. Fluidity of acetone mixtures at $0^{\circ}$.

\section{Solutions.}

In all cases conductivity measurements were made with solutions from solvents which were distilled on the same or the preceding day. Solvents and solutions were kept in bottles of Jena glass. In mixing solvents and in making solutions, they were placed in a $20^{\circ}$ bath for some time before diluting to the mark on the flask.

In designating mixed solvents, percentage by volume is understood.

An examination of the published viscosity data for mixed solrents will show that there are slight differences between the values given by different investigators,

1) Loc. cit.

2) Dissertation, Lausanne 1905. 
Conductivity and viscosity of dilute solutions of lithium nitrate, etc. 397 although those given by any one person are generally consistent among themselres. It is probable that such discrepancies are caused chiefly by differences in the amount and kind of unavoidable impurities in the solvents. For this reason we hare determined the viscosity of all of our solvents, and the data given in table 1 are those which have been obtained in this investigation. Figures 1 and 2 are drawn from these data.

In table 1, the symbols have the following significance : $\eta 0^{\circ}$ is the coefficient of viscosity at $0^{\circ}, \eta 25^{\circ}$ that at $25^{\circ}, \Phi 0^{\circ}$ the fluidity at $0^{\circ}$, and $\Phi 25^{\circ}$ that at $25^{\circ}$. The temperature coefficient of

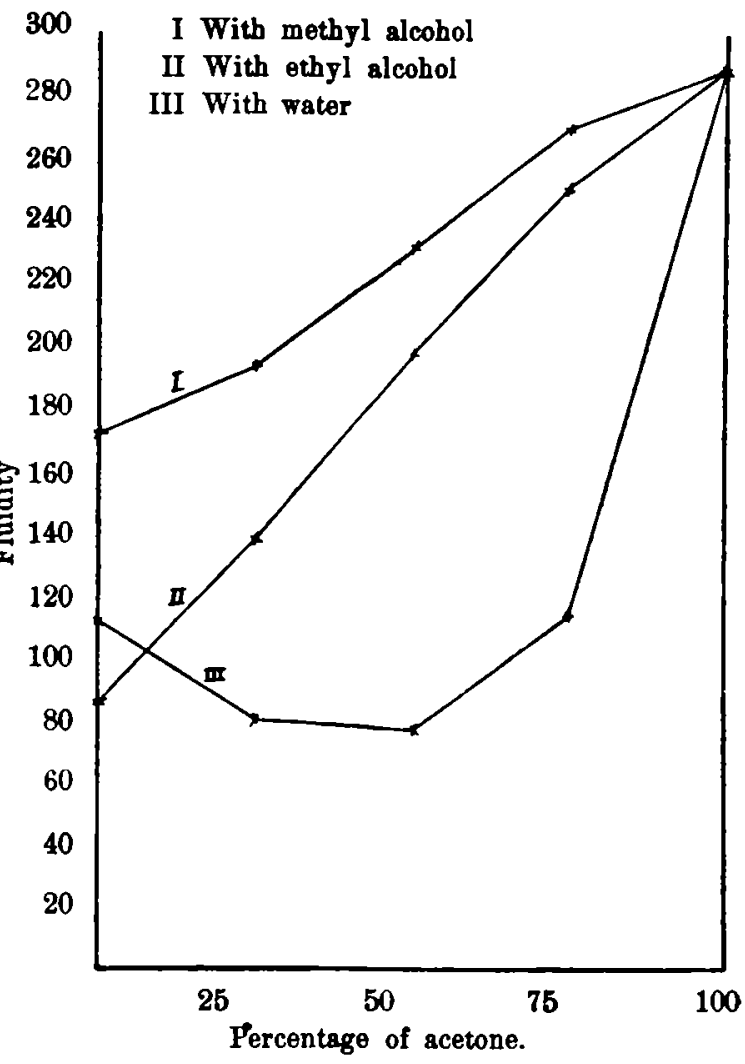

Fig. 2. Fluidity of acetone mixtures at $25^{\circ}$. fluidity is the change in fluidity per degree, divided by the fluidity at $0^{\circ}$.

\section{Table 1.}

Viscosity and fluidity of acetone mixtures at $0^{\circ}$ and $25^{\circ}$.

\begin{tabular}{cccccr}
$\%$ Acetone & $\eta 0^{\circ}$ & $\eta 25^{\circ}$ & $\Phi 0^{\circ}$ & $\Phi 25^{\circ}$ & Temp. Co \\
& \multicolumn{5}{c}{ With methyl alcohol. } \\
0 & 0.00857 & 0.00583 & 116.71 & 171.60 & 0.0176 \\
25 & 0.00734 & 0.00517 & 136.22 & 193.24 & 0.0167 \\
50 & 0.00596 & 0.00433 & 167.76 & 231.01 & 0.0151 \\
75 & 0.00471 & 0.00370 & 212.29 & 270.12 & 0.0109 \\
100 & 0.00429 & 0.00346 & 233.21 & 288.95 & 0.0096
\end{tabular}




\begin{tabular}{|c|c|c|c|c|c|}
\hline$\%$ Acetone & $\eta 0^{\circ}$ & $\begin{array}{c}\eta 25^{\circ} \\
\text { With et }\end{array}$ & $\begin{array}{c}\Phi 0^{\circ} \\
\text { alcohol }\end{array}$ & $\Phi 25^{\circ}$ & Temp. Coeff. \\
\hline 0 & 0.02103 & 0.01180 & 47.56 & 84.74 & 0.0313 \\
\hline 25 & 0.01131 & 0.00726 & 88.43 & 137.77 & 0.0223 \\
\hline 50 & 0.00725 & 0.09506 & 137.92 & 197.48 & 0.0173 \\
\hline 75 & 0.00522 & 0.00398 & 191.54 & 251.29 & 0.0125 \\
\hline 100 & 0.00429 & 0.00346 & 233.21 & 288.95 & 0.0096 \\
\hline \multicolumn{6}{|c|}{ With water. } \\
\hline 25 & 0.02908 & 0.01250 & 34.38 & 79.89 & 0.0529 \\
\hline 50 & 0.03005 & 0.01305 & $33 \cdot 28$ & $76 \cdot 63$ & 0.0521 \\
\hline 75 & 0.01659 & 0.00885 & 60.29 & 112.97 & 0.0349 \\
\hline 100 & 0.00429 & 0.00346 & $233 \cdot 21$ & 288.95 & 0.0096 \\
\hline
\end{tabular}

In the conductivity tables, nolecular conductivities are indicated, and $V$ is the number of liters of solution containing a gram-molecule of the electrolyte. The temperature coefficient of conductivity is the change in molecular conductivity per degree, divided by the molecular conductivity at $0^{\circ}$.

The first compound that we studied in this connection was lithium nitrate, and the sample used was Kahlbaum's preparation, which after testing was dried to constant weight at $150^{\circ}$.

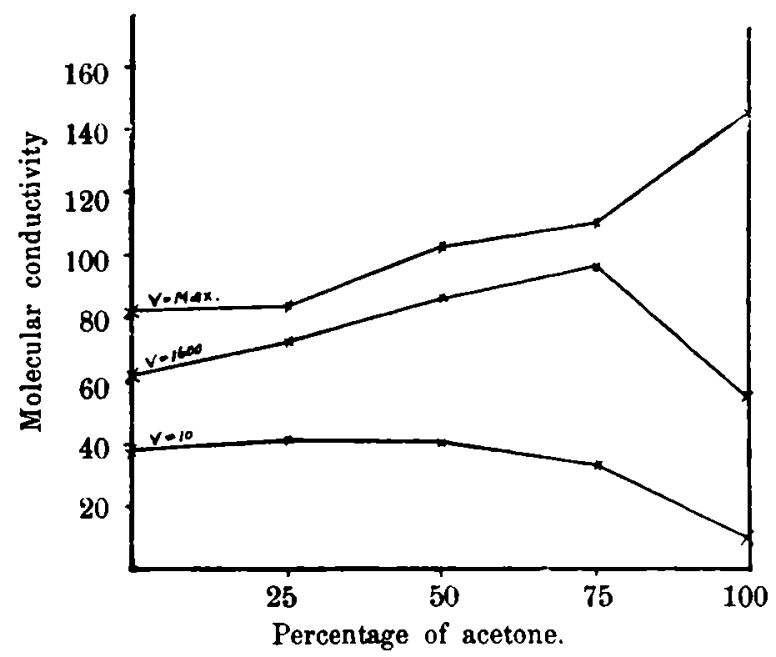

Fig. 3. Conductivity of lithium nitrate in mixtures of acetone and methyl alcohol at $0^{\circ}$.

The conductivity of lithium nitrate in mixtures of acetone with mothyl alcohol, etbyl alcohol, and water, respectively, was determined by Jones and Bingham ${ }^{1}$ ), using solutions whose concentration varied

y) Loc. cit. 
Conductivity and viscosity of dilute solutions of lithium nitrate, etc. 399 from $V=10$ to $V=1600$. The results are as already indicated, namely, that the form of the curves representing molecular conduc-

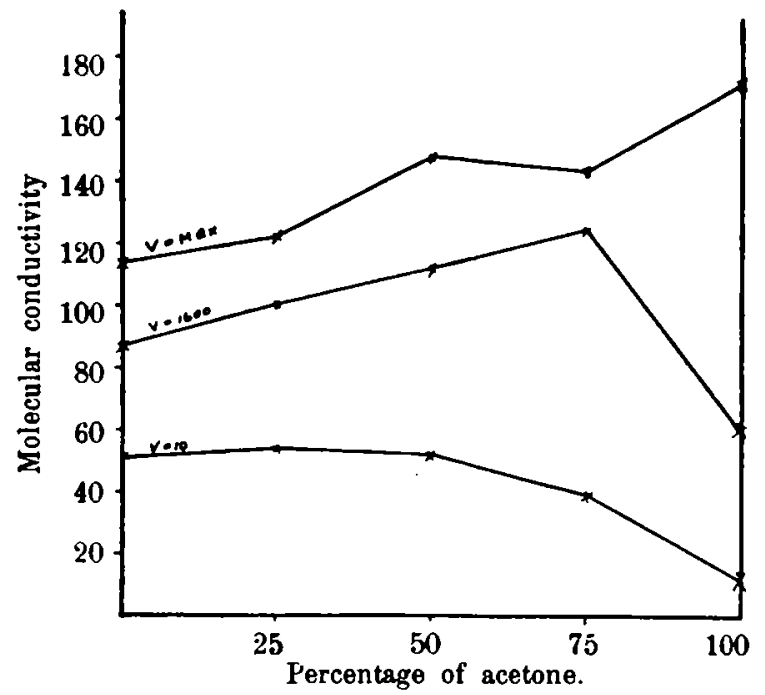

Fig. 4. Conductivity of lithium nitrate in mixtures of acotone and methyl alcohol at $25^{\circ}$.

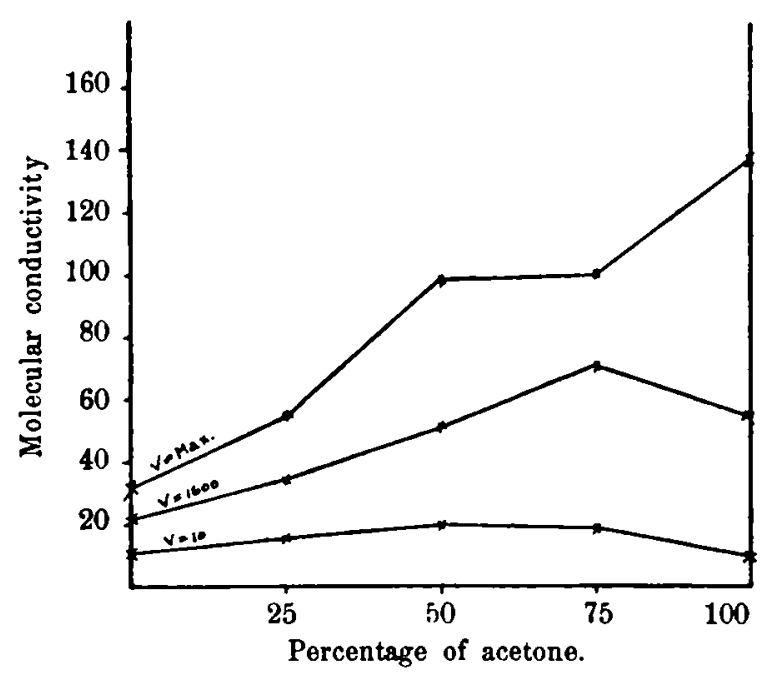

Fig. 5. Conductivity of lithium nitrate in mixtures of acetone and ethyl alcohol at $0^{\circ}$.

tivity for different percentages of acetone was different from that of the fluidity curves; in that conductivities in acetone were decidedly less than normal, and that no known dilution law would apply to the 
more concentrated solutions. We have used the same solvents and mixtares of solvents, and hare measured the conductivities at dilutions as

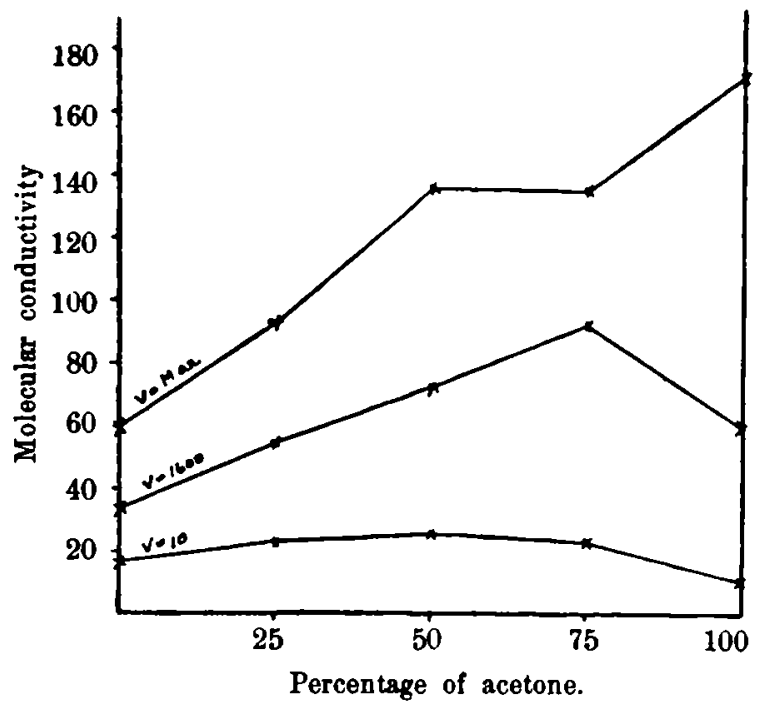

Fig. 6. Conductivity of lithium nitrate in mixtures of acetone and ethyl alcohol at $25^{\circ}$.

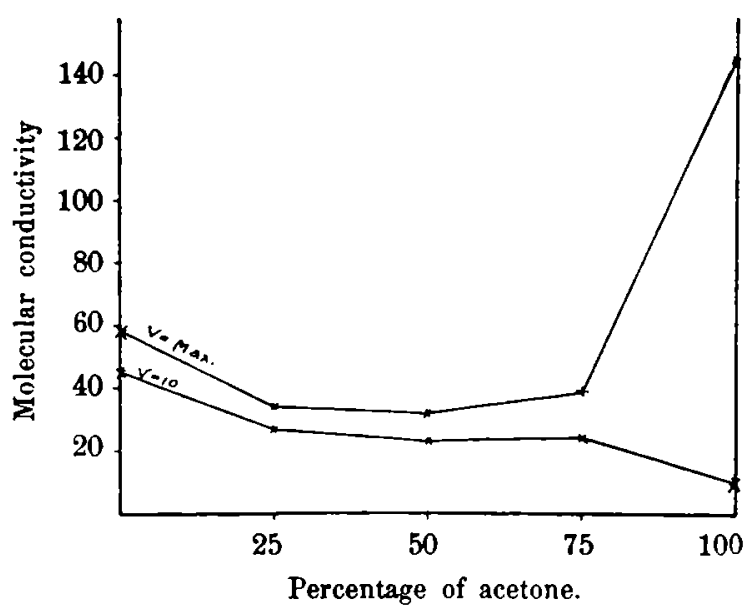

Fig. 7. Conductivity of lithium nitrate in mixtures of acetone and water at $0^{\circ}$.

high as was possible with any fair degree of accuracy, considering the conductivity of the solvent. The results are shown in tables 2 to 5 and 
Conductivity and riscosity of dilute solutions of lithinm nitrate, etc. 401 in figures 3 to 8 , inclusive. In the figures, the curves for $\nabla=10$ and $V=1600$ are drawn from the data of Jones and Bingham, and

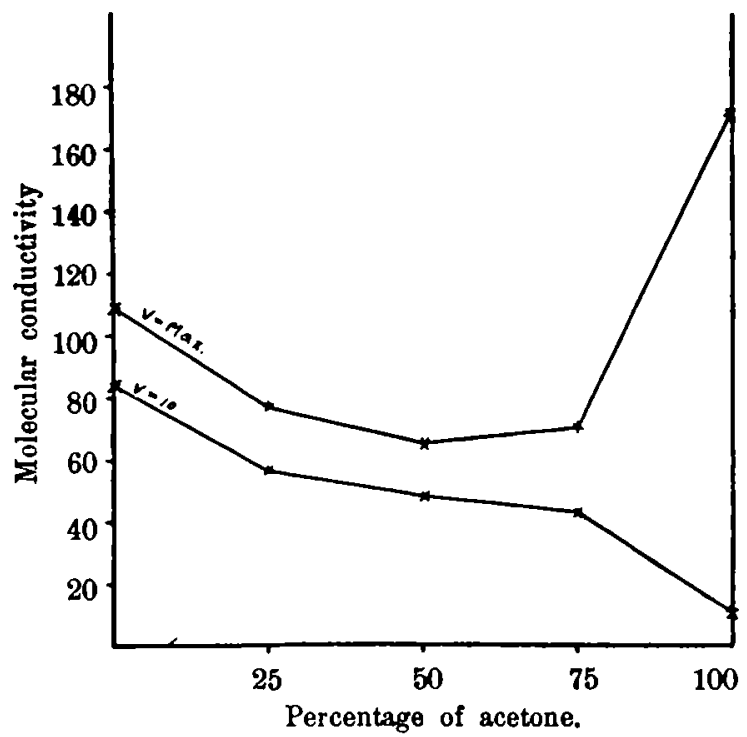

Fig. 8. Conductivity of lithium nitrate in mixtures of acetone and water at $25^{\circ}$.

are given here in order to show the abnormality produced by acetone as a solvent, and the striking change in the conductivity as the dilution increases.

Table 2.

Conductivity of lithium nitrate in mixtures of acetone and methyl alcohol.

At $0^{\circ}$.

\begin{tabular}{|c|c|c|c|c|c|}
\hline \multicolumn{6}{|c|}{$\%$ Acetone. } \\
\hline $\boldsymbol{V}$ & $0 \%$ & $25 \%$ & $50 \%$ & $75 \%$ & $100^{\circ}:$ \\
\hline 2500 & 63.4 & 69.6 & 87.0 & 96.8 & 61.0 \\
\hline 5000 & $66 \cdot 1$ & $71 \cdot 8$ & 91.5 & 101.5 & $76 \cdot 9$ \\
\hline 10000 & 68.1 & 78.8 & 99.4 & 103.5 & $94 \cdot 1$ \\
\hline 30000 & 81.6 & 84.3 & 103.0 & 110.9 & - \\
\hline 50000 & 83.0 & 83.8 & - & - & 129.8 \\
\hline 100000 & - & - & - & - & 146.5 \\
\hline
\end{tabular}

At $25^{\circ}$.

$\begin{array}{rccccc}2500 & 88.6 & 97.2 & 122.7 & 124.5 & 65.9 \\ 5000 & 92.5 & 100.1 & 132.5 & 131.1 & 85.7 \\ 10000 & 94.3 & 107.9 & 144.0 & 133.7 & 105.1 \\ 30000 & 113.2 & 121.5 & 138.0 & 142.6 & - \\ 50000 & 114.0 & 114.5 & - & - & 153.6 \\ 100000 & - & - & - & - & 171.8 \\ \text { Zeitschrift f. physik. Chemie. LxuX. } & & & & 26\end{array}$


Table 3.

Conductivity of lithinm nitrate in mixtures of acetone and ethyl alcohol.

\begin{tabular}{|c|c|c|c|c|c|}
\hline & & & & & \\
\hline $\boldsymbol{V}$ & $0 \%$ & $25 \%$ & $50 \%$ & $75^{\circ}$ : & $100 \%$ \\
\hline 2500 & $22 \cdot 2$ & 35.9 & $53 \cdot 0$ & - & 61.0 \\
\hline 5000 & 22.7 & 38.0 & $56 \cdot 1$ & 79.8 & 76.9 \\
\hline 10000 & $24 \cdot 1$ & 38.7 & $57 \cdot 3$ & $81 \cdot 6$ & 94.1 \\
\hline 30000 & $28 \cdot 1$ & - & - & 80.6 & - \\
\hline 50000 & 27.2 & 43.4 & 64.9 & 79.7 & 129.8 \\
\hline 100000 & $32 \cdot 0$ & $55 \cdot 0$ & 71.9 & $100 \cdot 0$ & 146.5 \\
\hline 200000 & - & - & 99.3 & - & - \\
\hline & & & & & \\
\hline 2500 & $37 \cdot 4$ & $55 \cdot 5$ & 74.5 & $97 \cdot 3$ & $65 \cdot 9$ \\
\hline 5000 & 38.3 & 58.1 & 79.3 & 105.2 & 85.7 \\
\hline 10000 & 40.0 & 59.4 & $83 \cdot 3$ & 109.0 & 105.1 \\
\hline 30000 & 48.0 & - & - & 106.5 & - \\
\hline 50000 & $44.7 ?$ & 68.5 & 93.4 & 112.8 & $153 \cdot 6$ \\
\hline 100000 & $60 \cdot 1$ & $93 \cdot 0$ & 105.1 & $135 \cdot 4$ & 171.8 \\
\hline 200000 & - & - & $136 \cdot 1$ & - & - \\
\hline
\end{tabular}

Table 4.

Conductivity of lithium nitrate in mixtures of acetone and water.

At $0^{\circ}$.

$\%$ Acetone.

$\begin{array}{rccccc}\boldsymbol{V} & 0 \% & \mathbf{2 5} \% & 50^{\circ} & \mathbf{7 5} & 100 \% \\ 2500 & 56.9 & 34.1 & 29.9 & 37.2 & 61.0 \\ 5000 & 58.4 & 34.2 & 31.4 & 37.6 & 76.9 \\ 10000 & 58.5 & 39.5 & 31.8 & 38.7 & 94.1 \\ 50000 & - & - & - & - & 129.8 \\ 100000 & - & - & - & - & 146.5 \\ & & & \text { At } 25^{\circ} . & & \\ 2500 & 104.6 & 73.4 & 61.6 & 66.7 & 65.9 \\ 5000 & 108.3 & 74.7 & 64.4 & 69.3 & 85.7 \\ 10000 & 108.7 & 76.3 & 64.8 & 69.6 & 105.1 \\ 50000 & - & - & - & - & 153.6 \\ 100000 & - & - & - & - & 171.8\end{array}$

\section{Table 5.}

Temperature coefficients of conductivity of lithium nitrate.

\begin{tabular}{|c|c|c|c|c|c|}
\hline $\boldsymbol{V}$ & $0 \%$ & $\begin{array}{l}25 \% \\
\text { one a }\end{array}$ & $50^{\circ}$ & $75^{\circ}: 0$ & $100 \%$ \\
\hline 2500 & 0.0159 & 0.0159 & 0.0164 & 0.0115 & 0.0032 \\
\hline 5000 & 0.0159 & 0.0157 & 0.0179 & 0.0116 & 0.0046 \\
\hline 10000 & 0.0153 & 0.0147 & 0.0182 & 0.0117 & 0.0047 \\
\hline 30000 & 0.0155 & 0.0176 & 0.0136 & 0.0114 & - \\
\hline 50000 & 0.0149 & 0.0146 & - & - & 0.0073 \\
\hline 100000 & - & - & - & - & 0.0070 \\
\hline
\end{tabular}


Conductivity and viscosity of dilute solutions of lithium nitrate, etc. 403

$\begin{array}{rccccc}V & 0 \% & 25 \% & 50 \% & 75 \% & 100 \% \\ 2500 & 0.0274 & 0.0218 & 0.0162 & - & \text { See above } \\ 5000 & 0.0275 & 0.0212 & 0.0166 & 0.0127 & " \\ 10000 & 0.0264 & 0.0205 & 0.0181 & 0.0134 & " \\ 30000 & 0.0283 & - & - & 0.0128 & " \\ 50000 & 0.0257 & 0.0231 & 0.0175 & 0.0161 & " \\ 100000 & 0.0351 & 0.0276 & 0.0184 & 0.0142 & " \\ & & \text { In acetone and water. } & & \\ 2500 & 0.0335 & 0.0461 & 0.0426 & 0.0317 & \text { See above } \\ 5000 & 0.0342 & 0.0473 & 0.0420 & 0.0337 & ", \\ 10000 & 0.0343 & 0.0511 & 0.0415 & 0.0319 & ",\end{array}$

In the solutions in pure water and in pure acetone it would seem that complete dissociation has been very nearly attained. In water solution the value for $\mu_{\infty}$ at $18^{\circ}$, calculated from the law of $\mathrm{K}_{0 h l}$ rausch and by use of the constants for the ions of lithium nitrate as given by him ${ }^{1}$ ), is 95 . The corresponding ralue, calculated from our highest conductirity at $0^{\circ}$, by use of the temperature coefficient, is 94 . In the solutions other than in water and acetone complete dissociation has not been reached, but we have approached it closely enough that the properties of the completely dissociated solution may be predicted. The conductivity curves bave assumed nearly the same form as the fluidity curres for the solvents.

In order to test the applicability of Ostwald's dilution law, the values of $K=\frac{a^{2}}{(1-a) v}$ hare been calculated for the solutions of lithium nitrate in acetone, from all available data. In table 6 the values for $\mu_{v}$ from $V=10$ to $V=1600$, inclusive, are taken from the paper of Jones and Binghan. From this point the values are those which have been obtained in this investigation.

Table 6.

Ionization constant for lithium nitrate in acetone. At $0^{\circ}$.

At $25^{\circ}$.

$\begin{array}{rccccccc}\boldsymbol{V} & K \times 10^{8} & \boldsymbol{V} & K \times 10^{\mathrm{s}} & \boldsymbol{V} & \boldsymbol{K} \times 10^{3} & \boldsymbol{V} & K \times 10^{8} \\ 10 & 0.541 & 1600 & 0.168 & 10 & 0.670 & 1600 & 0.130 \\ 50 & 0.235 & 2500 & 0.120 & 50 & 0.195 & 2500 & 0.096 \\ 100 & 0.198 & \mathbf{5} 000 & 0.117 & 100 & 0.156 & \mathbf{5 0 0 0} & 0.098 \\ 200 & 0.186 & 10000 & 0.116 & 200 & 0.134 & 10000 & 0.096 \\ 400 & 0.165 & 50000 & 0.145 & 400 & 0.115 & 50000 & 0.147 \\ 800 & 0.179 & & & 800 & \mathbf{0 . 1 2 6} & & \end{array}$

1) Sitzungsber. d. K. Preuss. Akad. d. Wiss. Math. Kl. 1904, 574 u. 582. 
It will be seen that $K$ becomes practically constant at $V=200$, for solutions at both $0^{\circ}$ and $25^{\circ}$; which would indicate that the highest ralue for $\mu_{v}$, that obtained at $V=100000$, is not far from the maximum molecular conductivity. The fact that $K$ decreases rapidls at first, may be explained on the general ground that Ostwald's dilution law is not applicable to solutions of strong electrolytes, or upon the assumption of polymerization of the electrolyte. It will appear later that there is reason for the latter view.

In table 7 is given the calculated product of riscosity and molecular conductivity for all of the solutions. In these calculations we have used, in each case, the viscosity of the solrent, which is practically identical with that of the dilute solution, and hare taken for $\mu_{v}$ the highest value which has been obtained in this work.

Table 7.

$\eta \cdot \mu_{,}$for lithium nitrate in mixed solvents.

\begin{tabular}{rrrrrrr}
$\%$ Acetone & $\mu_{v} 0^{\circ}$ & $\eta 0^{\circ}$ & $\eta \cdot \mu_{v}$ & $\mu_{v} 25^{\circ}$ & $\eta 25^{\circ}$ & $\eta \cdot \mu_{v}$ \\
& \multicolumn{5}{c}{ In acetnne and methyl alcohol. } \\
0 & 83 & 0.0086 & 0.69 & 114 & 0.0058 & 0.65 \\
25 & 84 & 0.0073 & 0.61 & 122 & 0.0052 & 0.63 \\
50 & 103 & 0.0060 & 0.62 & 144 & 0.0043 & 0.62 \\
75 & 111 & 0.0047 & 0.52 & 143 & 0.0037 & 0.53 \\
100 & 146 & 0.0043 & 0.63 & 172 & 0.0035 & 0.60
\end{tabular}

In acetone and etbyl alcohol.

\begin{tabular}{|c|c|c|c|c|c|c|}
\hline 0 & 32 & 0.0210 & 0.67 & 60 & 0.0118 & 0.71 \\
\hline 25 & 55 & 0.0113 & 0.62 & 93 & 0.0073 & 0.71 \\
\hline 50 & 100 & 0.0072 & 0.72 & 136 & 0.0051 & 0.69 \\
\hline 75 & 100 & 0.0052 & 0.52 & 135 & 0.0040 & 0.54 \\
\hline 100 & 146 & 0.0043 & 0.63 & 172 & 0.0035 & $0-60$ \\
\hline \multicolumn{7}{|c|}{ In acetone and water. } \\
\hline 0 & 58 & 0.0178 & 1.03 & 108 & 0.0089 & 0.96 \\
\hline 25 & 34 & 0.0291 & 0.99 & 76 & 0.0125 & 0.95 \\
\hline 50 & 32 & 0.0300 & 0.96 & 65 & 0.0131 & 0.85 \\
\hline 75 & 39 & 0.0166 & 0.65 & 70 & 0.0088 & 0.62 \\
\hline 100 & 146 & 0.0043 & 0.63 & 172 & 0.0035 & 0.60 \\
\hline
\end{tabular}

The product of riscosity and molecular conductivity is seen to be nearly a constant, for mixtures of acetone with methyl alcohol and with ethyl alcohol. This constant is independent of temperature and its value is nearly 0.70, - the value found by $\mathrm{W}$ alden for tetraethyl ammonium iodide in a large number of organic solrents. For mixtures of acetone with water, the product raries between about 1.00 , the value for water, and about 0.60 , that for acetone. The product for water is 
also shown to be the same as Walden's constant for water solutions. It is probable that, if complete dissociation could have been obtained in acetone, the product for this solution would have been found to be nearly 0.70 , and that the product for mixtures of acetone and water would conform to the rule of mixtures. We have no explanation to offer for the fact that water differs so strikingly from the organic solvents, with respect to the numerical value of the product of maximum molecular conductivity and riscosity.

In order to test the assumption that the low conductivity shown by ordinary solutions of lithium nitrate in acetone is due to association of the salt, the molecular weight of lithium nitrate in acetone was de-

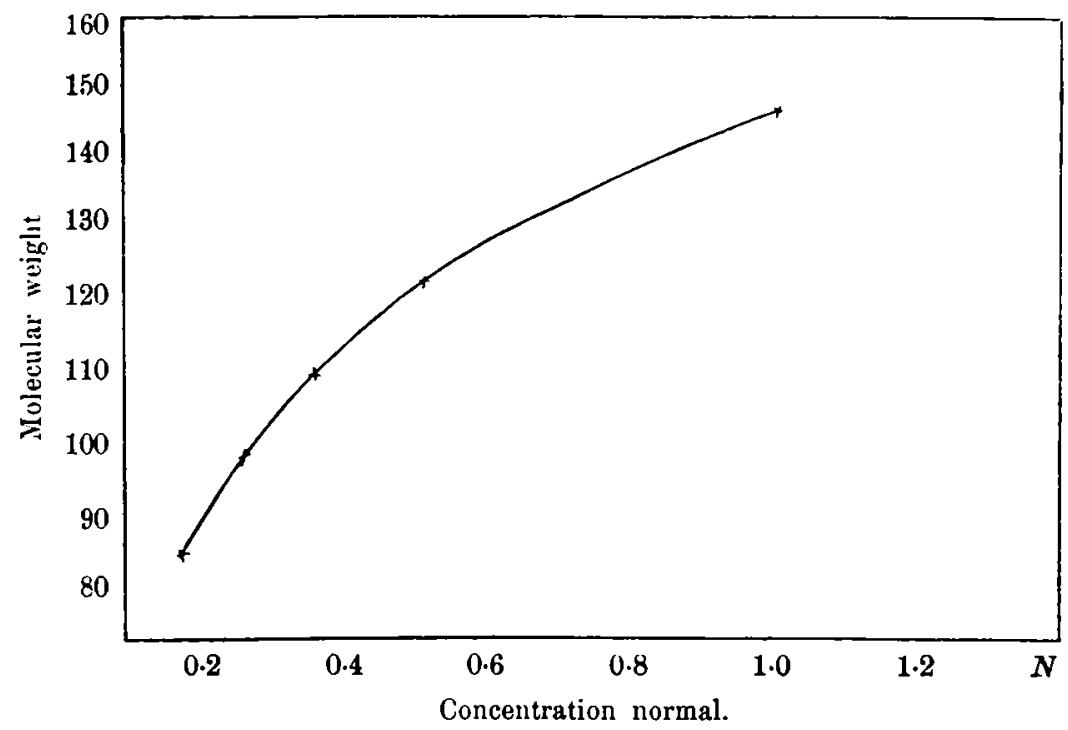

Fig. 9. Molecular weight of lithium nitrate in acetone.

termined by the boiling-point method. The apparatus used was the apparatus designed by $J_{0 n} \mathrm{~s}^{1}$ ), the thermometer being the Beckmann instrument, graduated to $0.01^{\circ}$. The boiling-point constant for acetone was taken as 17.25 , which is that found in a redetermination by $J \circ n \theta \mathrm{S}^{2}$ ). The usual corrections were made for changes in barometric pressure. The results are shown in table 8 , and the molecular weights are plotted against concentrations in figure 9 .

1) Amer. Chem. Journ. 19, 581 (1897); Zeitschr. f. physik. Chemie \$1, 119 (1899).

z) Amer. Chem. Journ. 27, 16 (1902). 
Table 8.

Molecular weight of lithium nitrate in acetone.

$\begin{array}{ccccc}\text { Acetone } & \text { LiNO } & \text { Concentration } & \text { B. P. Rise } & \text { Molecular } \\ \text { grams } & \text { grams } & \text { normal } & \text { degrees } & \text { weight } \\ 58.07 & \mathbf{0 . 3 6 2 5} & 0.09 & 0.130^{\circ} & 83.1 \\ \mathbf{5 2 . 7 4} & 0.7076 & 0.19 & 0.233 & 99.3 \\ \mathbf{4 9 . 9 9} & \mathbf{1 . 0 6 4 0} & 0.30 & 0.326 & 112.6 \\ \mathbf{4 6 . 3 0} & \mathbf{2 . 2 0 3 3} & \mathbf{0 . 4 8} & 0.451 & 127.1 \\ \mathbf{5 4 . 3 5} & \mathbf{3 . 9 2 2 9} & 1.05 & 0.805 & 154.7\end{array}$

The normal molecular weight of lithium nitrate is 69.07 . The fact that, even in the most dilute solution which could be used with accuracy $(0.09 \mathrm{~N})$, the molecular weight is greater than this number is significant. If it be remembered that a portion of the salt is also ionized, and that the molecular weight as obtained by the boiling-point method is the average weight of associated molecules, single molecules and ions, existing simultaneously in the solution, it will readily be surmised that there must be a certain degree of association at much greater dilutions. This would explain the departure from the dilution law in those solutions in which the association has not entirely disappeared.

It has already been stated that cadminm iodide was found br Jones to be associated when dissolved in acetone. We hare studied

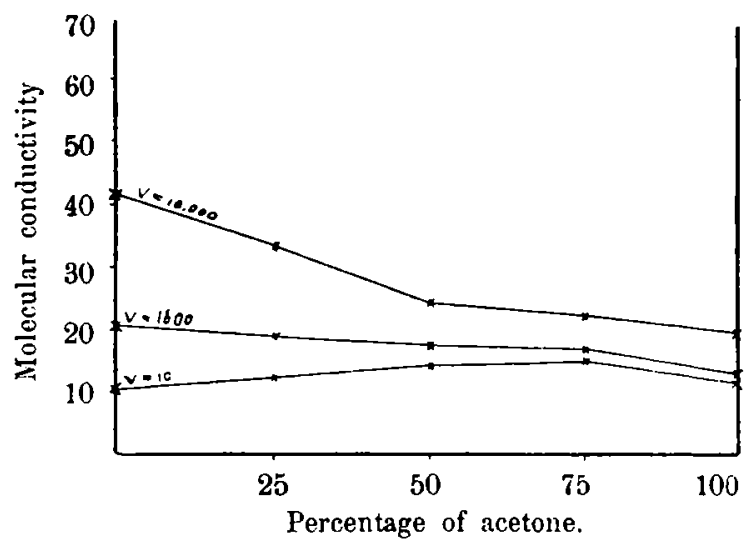

Fig. 10. Conductivity of cadmium iodide in mixtures of acetone and methyl alcohol at $0^{\circ}$.

the conductivity of cadmium iodide in acetone and in binary mixtures containing acetone, in order to determine whether such solutions are analogous to those of lithium nitrate, as they should be if the proposed explanation of the peculiar beharior of the latter is correct. The results 
Conductivity and viscosity of dilute solutions of lithium nitrate, etc. 407 of the conductivity measurements are shown in tables 9 to 17 , and in figures 10 to 15 , inclusive.

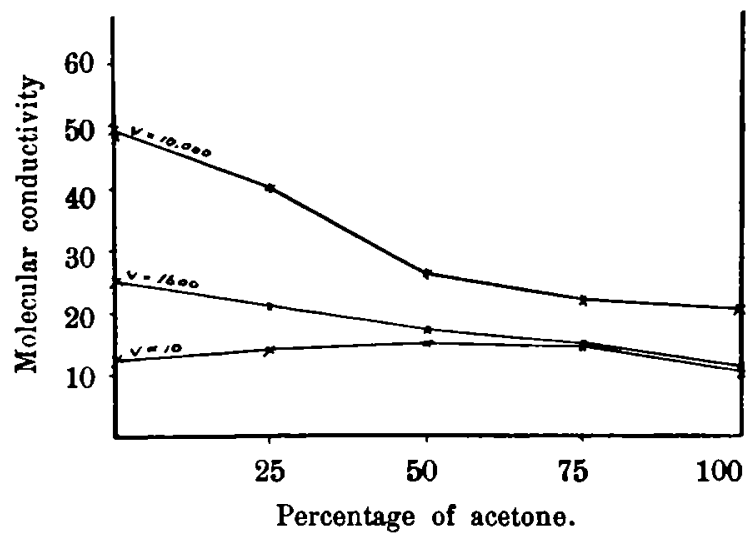

Fig. 11. Conductivity of cadmium iodide in mixtures of acetone and methyl alcohol at $25^{\circ}$.

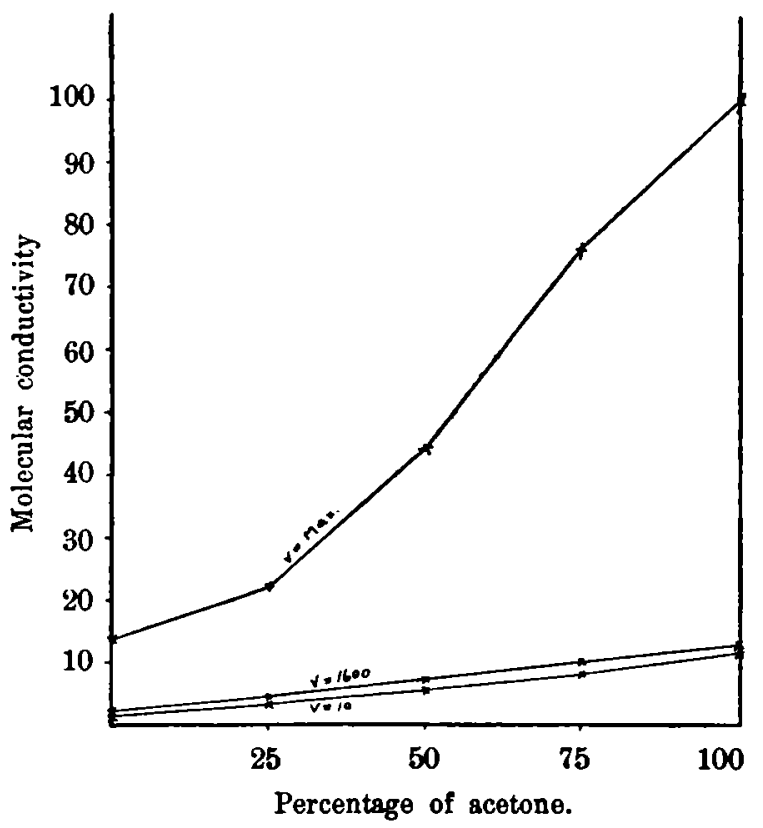

Fig.12. Conductivity of cadmium iodide in mixtures of acetone and ethyl alcohol at $0^{\circ}$. 


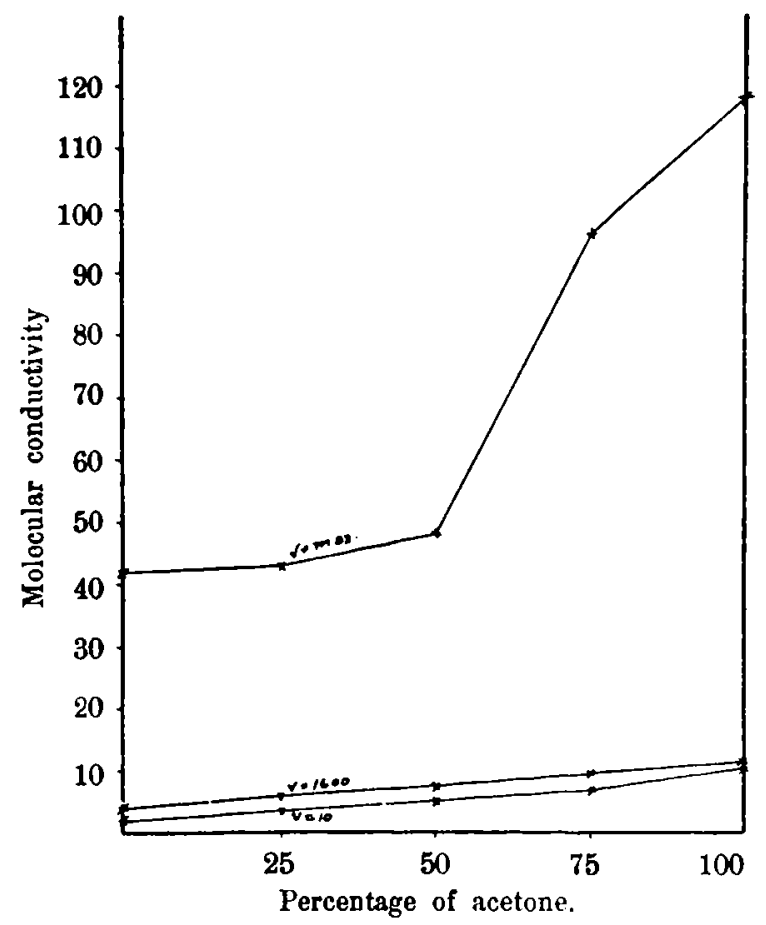

Fig. 13. Conductivity of cadmium iodide in nixtures of acetone and ethyl alcohol at $25^{\circ}$.

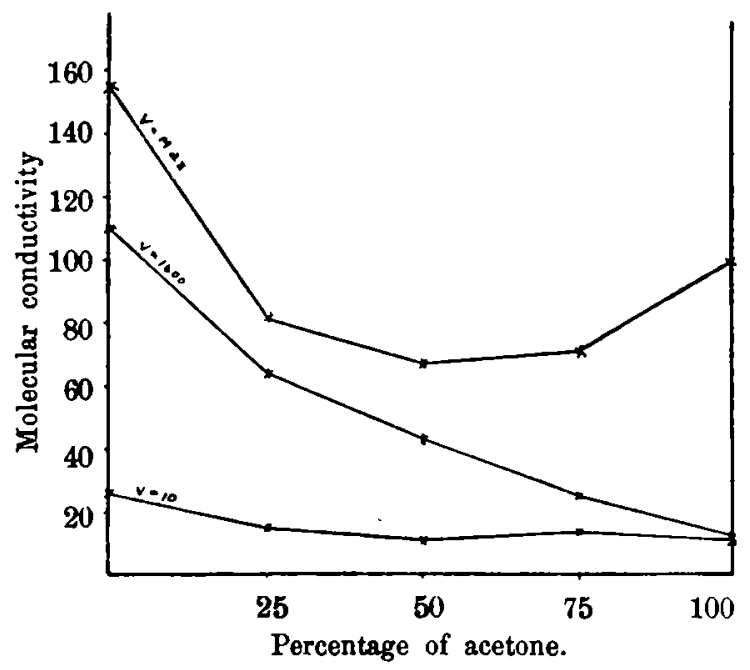

Fig. 14. Conductivity of cadmium iodide in mixtures of acetone and water at $0^{\circ}$. 
Conductivity and viscosity of dilute solutions of lithium nitrate, etc. 409

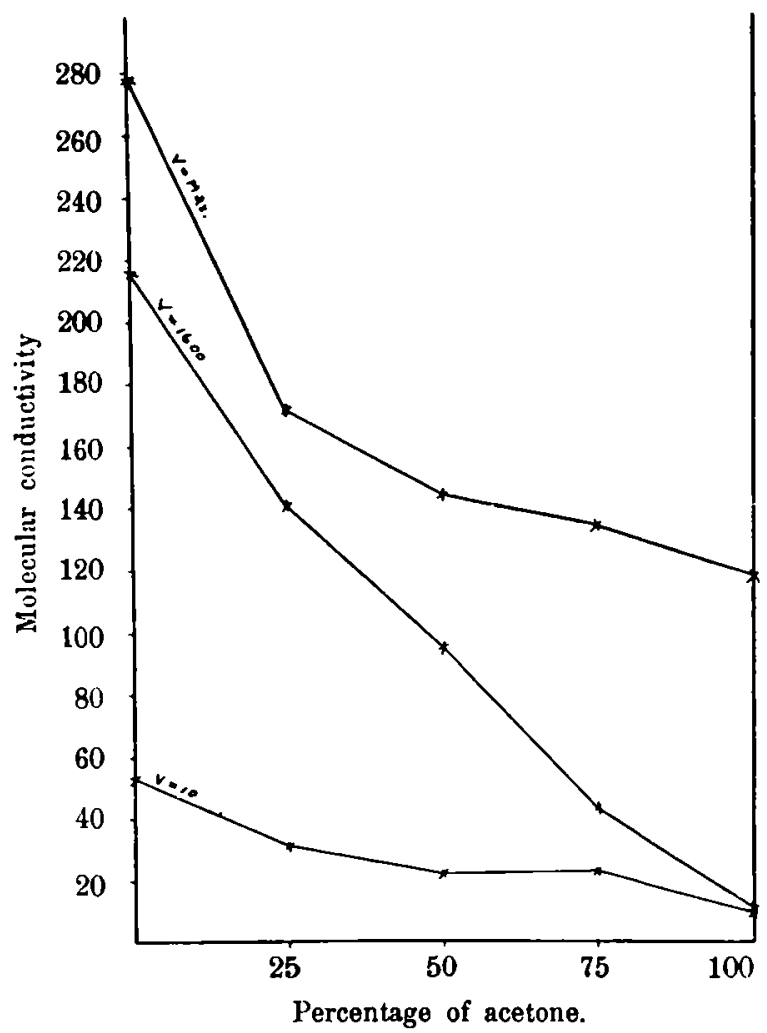

Fig. 15. Conductivity of cadmium iodide in mixtures of acetone and water at $25^{\circ}$.

Table 9 .

Conductivity of cadmium iodide in mixtures of acetone and methyl alcohol at $0^{\circ}$.

\begin{tabular}{|c|c|c|c|c|c|}
\hline \multicolumn{6}{|c|}{;o Acetone. } \\
\hline $\boldsymbol{V}$ & $0 \%$ & $25 \%$ & $50 \%$ & $75 \%$ & $100 \%$ \\
\hline 10 & 10.31 & 12.39 & $14 \cdot 31$ & 15.13 & 11.56 \\
\hline 50 & 11.72 & 13.94 & $15 \cdot 63$ & $16 \cdot 36$ & $12 \cdot 10$ \\
\hline 100 & $12 \cdot 34$ & 14.35 & 15.89 & 16.47 & 11.88 \\
\hline 200 & $13 \cdot 01$ & 14.44 & $15 \cdot 83$ & $16 \cdot 48$ & $12 \cdot 22$ \\
\hline 400 & 14.92 & 15.56 & $16 \cdot 62$ & 16.89 & 12.11 \\
\hline 800 & $17 \cdot 42$ & $16 \cdot 86$ & 17.05 & 16.90 & 12.63 \\
\hline 1600 & 20.83 & 18.77 & 17.37 & 17.00 & 12.87 \\
\hline 2500 & $25 \cdot 60$ & 21.09 & 18.13 & $17 \cdot 19$ & 12.27 \\
\hline 5000 & 33.12 & 27.05 & $21 \cdot 2$ & 20.64 & $15 \cdot 35$ \\
\hline 10000 & 41.5 & 33.4 & $24 \cdot 2$ & 22.2 & 19.53 \\
\hline 30000 & 46.8 & 48.0 & 32.2 & $29 \cdot 3$ & 29.4 \\
\hline
\end{tabular}




$\begin{array}{cccccc}V & 0 \% & 25 \% & 50 \% & 75 \% & 100 \% \\ 50000 & 55.0 & 60.8 & 39.2 & 32.3 & 37.5 \\ 100000 & 62.7 & 94.3 & - & -- & 78.0 \\ 200000 & - & - & - & - & 93.0 \\ 400000 & - & - & - & - & 100.0\end{array}$

Table 10.

Conductivity of cadmium iodide in mixtures of acetone and methyl alcohol at $25^{\circ}$.

\begin{tabular}{|c|c|c|c|c|c|}
\hline$V$ & $0^{0}: 0$ & $25^{\circ}, 0$ & $50^{\circ}, 0$ & $75^{\circ}$. & $100 \%$ \\
\hline 10 & 12.42 & 14.03 & $15 \cdot 11$ & 14.68 & 10.29 \\
\hline 50 & $13 \cdot 66$ & $15 \cdot 16$ & $15 \cdot 75$ & $15 \cdot 19$ & $10 \cdot 15$ \\
\hline 100 & $14 \cdot 28$ & 15.46 & $16 \cdot 10$ & 14.96 & 9.92 \\
\hline 200 & 15.03 & 15.53 & 15.66 & 14.84 & 10.34 \\
\hline 400 & $17 \cdot 42$ & 16.59 & $16 \cdot 18$ & $15 \cdot 18$ & $10 \cdot 23$ \\
\hline 800 & 20.36 & 18.18 & $16 \cdot 76$ & 14.98 & $10 \cdot 88$ \\
\hline 1600 & 24.53 & 20.76 & $17 \cdot 32$ & 14.98 & $11 \cdot 16$ \\
\hline 2500 & 28.95 & 24.18 & $18 \cdot 14$ & 15.08 & $11 \cdot 64$ \\
\hline 5000 & $40 \cdot 0$ & 32.4 & 21.7 & 19.1 & 13.91 \\
\hline 10000 & $49 \cdot 2$ & 39.8 & $25 \cdot 9$ & $21 . \pi$ & 20.5 \\
\hline 30000 & 54.2 & $56 \cdot 6$ & $33 \cdot 1$ & $27 \cdot 6$ & 32.5 \\
\hline 50000 & $55 \cdot 9$ & $80 \cdot 6$ & $43 \cdot 3$ & 28.9 & $45 \cdot 4$ \\
\hline 100000 & 63.0 & 105.5 & - & - & $78 \cdot 6$ \\
\hline 200000 & - & - & ..- & - & 113.0 \\
\hline 400000 & - & - & - & - & 118.0 \\
\hline
\end{tabular}

Table 11.

Temperature coefficients of conductivity of cadmium iodide in mixtures of acetone and methyl alcohol.

\begin{tabular}{|c|c|c|c|c|c|}
\hline$V$ & $0^{\circ}$ & $25^{\circ}$ & $50 \%$ & $75 \%$ & $100 \%$ \\
\hline 10 & 0.0082 & 0.0051 & +0.0022 & -0.0011 & -0.0045 \\
\hline 50 & 0.0066 & 0.0038 & +0.0003 & -0.0030 & -0.0063 \\
\hline 100 & 0.0063 & 0.0031 & +0.0005 & -0.0036 & -0.0064 \\
\hline 200 & 0.0062 & 0.0031 & -0.0003 & -0.0039 & -0.0061 \\
\hline 400 & 0.0067 & 0.0026 & -0.0009 & -0.0040 & -0.0062 \\
\hline 800 & 0.0066 & 0.0031 & -0.0007 & -0.0045 & -0.0054 \\
\hline 1600 & 0.0071 & 0.0064 & -0.0001 & -0.0047 & -0.0053 \\
\hline 2500 & 0.0052 & 0.0059 & 0.0000 & -0.0049 & -0.0023 \\
\hline 5000 & 0.0083 & 0.0078 & +0.0009 & -0.0030 & -0.0039 \\
\hline 10000 & 0.0074 & 0.0077 & +0.0028 & -0.0009 & +0.0021 \\
\hline 30000 & 0.0063 & 0.0072 & +0.0011 & -0.0023 & +0.0046 \\
\hline 50000 & 0.0006 & 0.0130 & +0.0042 & -0.0042 & +0.0084 \\
\hline 100000 & 0.0002 & 0.0047 & - & - & +0.0066 \\
\hline 200000 & - & - & - & - & +0.0086 \\
\hline 400000 & $\longrightarrow$ & - & -- & - & +0.0072 \\
\hline
\end{tabular}


Table 12.

Conductivity of cadmitum iodide in mixtures of acetone and ethyl alcohol at $0^{\circ}$.

\begin{tabular}{|c|c|c|c|c|c|}
\hline$V$ & $0 \%$ & $25^{\circ}$ & $50^{\circ}$ & $75^{\circ} ; 0$ & $100 \%$ \\
\hline 10 & 1.69 & 3.43 & 5.58 & 8.15 & 11.56 \\
\hline 50 & 1.62 & $\mathbf{3 \cdot 3 7}$ & 5.51 & 7.97 & $12 \cdot 10$ \\
\hline 100 & 1.60 & 3.42 & $5 \cdot 52$ & 7.92 & 11.88 \\
\hline 200 & 1.67 & 3.49 & 5.63 & 7.98 & $12 \cdot 22$ \\
\hline 400 & 1.74 & 3.54 & $5 \cdot 86$ & $8 \cdot 16$ & $12 \cdot 11$ \\
\hline 800 & 1.93 & 4.11 & $6 \cdot 38$ & 8.57 & 12.63 \\
\hline 1600 & $2 \cdot 31$ & 4.63 & $7 \cdot 20$ & 10.01 & 12.87 \\
\hline 2500 & 2.28 & 5.42 & 9.41 & 10.52 & 12.27 \\
\hline 5000 & $4 \cdot 6$ & 7.0 & 13.0 & $13 \cdot 2$ & $15 \cdot 4$ \\
\hline 10000 & 7.8 & 8.4 & 16.0 & 21.8 & 19.5 \\
\hline 25000 & - & $15 \cdot 1$ & 26.5 & 29.4 & - \\
\hline 50000 & 13.9 & $22 \cdot 0$ & $43 \cdot 6$ & 60 & 37.5 \\
\hline 100000 & 10.4 & - & - & $76 \cdot 0$ & 78.0 \\
\hline 200000 & - & - & - & - & 93.0 \\
\hline 400000 & - & - & - & - & $100 \cdot 0$ \\
\hline
\end{tabular}

Table 13.

Conductivity of cadmium iodide in mixtures of acetone and ethyl alcohol at $25^{\circ}$. $\because$ Acetone.

\begin{tabular}{|c|c|c|c|c|c|}
\hline$V$ & $0^{0}{ }_{10}$ & $25^{\circ} .0$ & $50^{\circ}$ & $75^{\circ}$. & $100^{\circ}{ }_{10}$ \\
\hline 10 & 2.11 & 3.54 & $5 \cdot 19$ & 7.03 & 10.29 \\
\hline 50 & 2.00 & 3.40 & 4.91 & 6.58 & 10.15 \\
\hline 100 & 2.03 & 3.45 & 4.95 & 6.58 & 9.92 \\
\hline 200 & 2.16 & $3 \cdot 61$ & 4.97 & 6.65 & 10.34 \\
\hline 400 & 2.42 & $3 \cdot 87$ & $5 \cdot 53$ & 6.95 & $10 \cdot 23$ \\
\hline 800 & 2.97 & 4.78 & 6.27 & 6.48 & 10.88 \\
\hline 1600 & 4.02 & 5.93 & $7 \cdot 70$ & 9.62 & $11 \cdot 16$ \\
\hline 2500 & 4.75 & 7.58 & $11 \cdot 10$ & 10.64 & 11.64 \\
\hline 5000 & 9.33 & $11 \cdot 0$ & $17 \cdot 1$ & 15.5 & 13.9 \\
\hline 10000 & $15 \cdot 2$ & $14 \cdot 3$ & 21.5 & $26 \cdot 0$ & 20.5 \\
\hline 25000 & - & $15 \cdot 0$ & 34.5 & $35 \cdot 3$ & - \\
\hline 50000 & 41.7 & $43 \cdot 1$ & 58.3 & 75.0 & 45.4 \\
\hline 100000 & 42.0 & - & - & 96.0 & $78 \cdot 6$ \\
\hline 200000 & - & - & - & - & 113.0 \\
\hline 400000 & - & - & - & - & $118 \cdot 0$ \\
\hline
\end{tabular}

Table 14.

Temperature coefficients of conductivity of cadmiun iodide in mixtures of acetone and ethyl alcohol.

$\begin{array}{rccccc}V & 0 \% & 25 \% & \begin{array}{c}\text { \% Actone. } \\ 50 \%\end{array} & \mathbf{7 5 \%} & 100 \% \\ 10 & 0.0099 & 0.0013 & -0.0028 & -0.0055 & -0.0045 \\ 50 & 0.0094 & 0.0004 & -0.0044 & -0.0070 & -0.0063 \\ 100 & 0.0107 & 0.0004 & -0.0041 & -0.0067 & -0.0064 \\ 200 & 0.0118 & 0.0014 & -0.0047 & -0.0066 & -0.0061 \\ 400 & 0.0156 & 0.0037 & -0.0023 & -0.0059 & -0.0062\end{array}$




\begin{tabular}{|c|c|c|c|c|c|}
\hline$V$ & $0 \%$ & $25 \%$ & $50 \%$ & $75^{\circ}$ & $100^{\circ}, 0$ \\
\hline 800 & 0.0215 & 0.0065 & -0.0007 & -0.0097 & --0.0064 \\
\hline 1600 & 0.0296 & 0.0112 & +0.0028 & -0.0016 & -0.0053 \\
\hline 2500 & 0.0433 & 0.0157 & +0.0072 & +0.0005 & -0.0023 \\
\hline 5000 & 0.0413 & 0.0231 & +0.0127 & +0.0069 & -0.0039 \\
\hline 10000 & 0.0379 & 0.0282 & +0.0138 & +0.0077 & $+0.00-21$ \\
\hline 25000 & - & 0.0262 & +0.0120 & $\div 0.0080$ & - \\
\hline 50000 & 0.0800 & 0.0384 & +0.0135 & +0.0100 & $\div 0.0054$ \\
\hline 100000 & 0.1230 & - & - & +0.0105 & $+0.00+36$ \\
\hline 200000 & - & - & - & - & +0.0086 \\
\hline 400000 & - & - & - & - & +0.0072 \\
\hline
\end{tabular}

Table 15.

Conductivity of cadmium iodide in mixtures of acetone and water at $0^{\circ}$. $\%$ Acetone.

\begin{tabular}{|c|c|c|c|c|c|}
\hline $\boldsymbol{V}$ & $0^{\circ}$ 。 & $25 \%$ & $50^{\circ} \%$ & $75 \%$ & $100^{\circ} 。$ \\
\hline 10 & 25.95 & 15.00 & 11.40 & 14.17 & 11.56 \\
\hline 50 & 45.88 & 22.49 & 13.40 & 15.45 & 12.10 \\
\hline 100 & 58.16 & 29.26 & $15 \cdot 39$ & $16 \cdot 12$ & 11.88 \\
\hline 200 & $70 \cdot 6$ & $38 \cdot 13$ & 19.00 & 17.01 & 12.22 \\
\hline 400 & 83.0 & $47 \cdot 6$ & $24 \cdot 4$ & $18 \cdot 2$ & $12 \cdot 11$ \\
\hline 800 & $96 \cdot 3$ & 56.4 & 33.0 & 20.6 & $12 \cdot 63$ \\
\hline 1600 & 110.0 & $63 \cdot 9$ & $43 \cdot 3$ & 24.6 & 12.87 \\
\hline 2500 & $116 \cdot 1$ & 66.2 & $49 \cdot 3$ & 27.8 & 12.27 \\
\hline 5000 & 126.2 & 72.4 & 57.2 & $35 \cdot 6$ & 15.4 \\
\hline 10000 & $140 \cdot 6$ & $80 \cdot 8$ & 63.8 & $48 \cdot 3$ & 19.5 \\
\hline 25000 & $155 \cdot 2$ & - & 67.2 & 62.1 & - \\
\hline 50000 & - & - & -- & 71.0 & 37.5 \\
\hline 100000 & - & - & - & - & 78.0 \\
\hline 200000 & - & - & - & - & 93.0 \\
\hline 400000 & - & - & - & - & $100 \cdot 0$ \\
\hline
\end{tabular}

Table 16.

Conductivity of cadmium iodide in mixtures of acetone and water at $25^{\circ}$.

\begin{tabular}{|c|c|c|c|c|c|}
\hline$V$ & $0^{\circ}, 0$ & $25^{\circ}$ 。 & $\overline{\mathbf{D}} 0 \%$ & $75^{\circ}$ 。 & $100^{\circ}$ \\
\hline 10 & $52 \cdot 68$ & 30.65 & 21.90 & 23.08 & 10.29 \\
\hline 50 & 95.43 & 49.94 & $27 \cdot 12$ & 24.83 & 10.15 \\
\hline 100 & 119.95 & 65.65 & 32.46 & 25.98 & 9.92 \\
\hline 200 & 144.4 & 85.73 & 41.4 & 27.77 & 10.34 \\
\hline 400 & 167.8 & $105 \cdot 6$ & 54.5 & 30.14 & 10.23 \\
\hline 800 & 191.6 & 124.5 & 73.1 & 34.81 & 10.88 \\
\hline 1600 & $215 \cdot 8$ & 139.7 & 95.0 & 43.16 & $11 \cdot 16$ \\
\hline 2500 & 225.4 & $145 \cdot 6$ & $105 \cdot 8$ & 49.7 & $11 \cdot 64$ \\
\hline 5000 & 240.2 & 155.1 & $122 \cdot 1$ & 66.9 & 13.9 \\
\hline 10000 & 261.2 & $170 \cdot 6$ & $135 \cdot 2$ & 91.0 & 20.5 \\
\hline 25000 & 278.8 & - & $144 \cdot 2$ & 117.0 & - \\
\hline 50000 & - & - & - & 134.0 & $45 \cdot 4$ \\
\hline
\end{tabular}


Conductivity and viscosity of dilute solutions of lithium nitrate, etc. 413

$\begin{array}{cccccr}\boldsymbol{V} & 0 \% & 25 \% & 50 \% & 75 \% & 10 \%^{\circ} \text { \% } \\ 100000 & - & - & - & - & 78.6 \\ 200000 & - & - & - & - & 113.0 \\ 400000 & - & - & - & - & 118.0\end{array}$

Table 17.

Temperature coefficients of conductivity of cadmium iodide in mixtures of acetone and water.

\begin{tabular}{rccccc}
$\nabla$ & \multicolumn{5}{c}{$\%$} \\
10 & 0.0402 & 0.0417 & $\mathbf{0 . 0 3 6 9}$ & $\mathbf{0 . 0 2 5 1}$ & -0.0045 \\
50 & 0.0432 & 0.0488 & $\mathbf{0 . 0 4 0 9}$ & 0.0243 & -0.0063 \\
100 & 0.0424 & 0.0484 & $\mathbf{0 . 0 4 4 3}$ & 0.0238 & -0.0064 \\
200 & 0.0418 & 0.0499 & 0.0471 & 0.0253 & -0.0061 \\
400 & 0.0409 & 0.0487 & 0.0493 & 0.0261 & -0.0062 \\
800 & 0.0398 & 0.0412 & 0.0486 & 0.0275 & -0.0054 \\
1600 & 0.0385 & 0.0474 & 0.0477 & 0.0302 & -0.0053 \\
2500 & 0.0376 & 0.0479 & 0.0458 & 0.0315 & -0.0023 \\
5000 & 0.0361 & 0.0456 & 0.0454 & 0.0352 & -0.0039 \\
10000 & 0.0343 & 0.0444 & 0.0447 & 0.0353 & +0.0021 \\
25000 & 0.0319 & - & 0.0458 & 0.0355 & - \\
50000 & - & - & - & 0.0357 & +0.0084 \\
100000 & - & - & - & - & +0.0066 \\
200000 & - & - & - & - & +0.0086 \\
400000 & - & - & - & - & +0.0072
\end{tabular}

The conductivity of cadmium iodide in water has been studied by Lenz ${ }^{1}$ ), Grotrian ${ }^{2}$ ), Wershoven ${ }^{3}$ ), Zelinski and Krapiwin ${ }^{4}$ ), Fox ${ }^{5}$ ) and Jones and Lindsay ${ }^{6}$ ). Hittorf ${ }^{7}$ ) determined the apparent transport numbers of the anion in solutions of different concentrations, and concluded that, in the more concentrated solutions, double molecules exist, which-dissociate to $C d^{*}$ and $C d I_{4}^{\prime \prime}$. Lenz also believed that the more concentrated solutions contain complex anions. $\mathrm{McBain}{ }^{8}$ ), on the other hand, followed a different line of argument and decided that double molecules exist, but that they dissociate to form the ions $C d^{*}$ and $2 \mathrm{CdI}_{3}{ }^{\prime}$. The conclusion was reached that at greater dilutions these ions are also broken down into the simpler ions $C d^{\prime \prime}$ and $3 I^{\prime}$, resulting in a large increase in the molecular conductivity.

Bein $\left.{ }^{9}\right)$ also studied the transport numbers of the anion of cadmium iodide at different temperatures, and showed that there is no perceptible change between $20^{\circ}$ and $75^{\circ}$.

1) Mem. de St. Petersb. [7] 30, 64 (1882). 2) Wied. Ann. 18, 190 (1883).

3) Zeitschr. f. physik. Chemie 5, 481 (1890). 4) Ibid. 21, 35 (1896).

s) Ibid. 41, 458 (1902). 9 ) Amer. Chem. Journ. 28, 329 (1902).

3) Pogg. Ann. 106, 513 (1859).

8) Z. f. Elektroch. 11, 215 (1905). $\quad$ o) Wied. Ann. 46, 29 (1892). 
From the work of $K \ddot{\text { ummel }}{ }^{1}$ ) it is evident that the apparent transport numbers of the halogens reach their minimum values in solutions of the cadmium halides which vary in concentration from 0.01 normal to 0.002 normal. Since the abnormally large apparent transport number for the balogen is supposed to be due to the fact that cadmium migrates towards both electrodes, this accords with the idea held by Hittorf, Lenz, and McBain, that the complex anions break down with increasing dilution.

Herz and Lew $y^{2}$ ) carried out partition experiments with cadmium iodide in water and amyl alcohol, from the results of which they were led to conclude that complex ions are present in the water solution.

It is not believed that the highest values for molecular conductivity which have been obtained in the present work are, in any of the solutions except those in water, the ones corresponding to complete dissociation. McBain attributed to Zelinsky and Krapiwin the most accurate work on the conductivity of water solutions of cadnium iodide, and he regarded 278 , a value calculated from their results obtained at $18^{\circ}$, as the correct value for the maximum molecular conductivity at $25^{\circ}$. This corresponds with the results of our measurements, which gave 279 at $25^{\circ}$. It is evident, from an inspection of the values of $K$, calculated from Ostwald's dilution law, that this is very close to the maximum molecular conductivity. The regular decrease in the value of $K$ until the dilution reaches about 0.001 normal, may be attributed to the non-applicability of the dilution law of Ostwald to solutions of cadmium iodide; or may be explained by the assumption of molecular association and simple ionization, or of association accompanied by the formation of complex ions, the latter being the most probable cause.

\section{Table 18.}

Ionization constant for cadmium iodide in water.

\begin{tabular}{rcrc|rrrc} 
& \multicolumn{3}{c|}{ At $0^{\circ}$} & \multicolumn{5}{c}{ At $25^{0}$} \\
$V$ & $K \times 10^{2}$ & $V$ & $K \times 10^{2}$ & $V$ & $K \times 10^{2}$ & $V$ & $K \times 10^{2}$ \\
10 & 0.338 & 800 & 0.126 & 10 & 0.425 & 800 & 0.189 \\
50 & 0.257 & 1600 & 0.108 & 50 & 0.352 & 1600 & 0.166 \\
100 & 0.223 & 2500 & 0.089 & 100 & 0.324 & 2500 & 0.134 \\
200 & 0.194 & 5000 & 0.071 & 200 & 0.275 & 5000 & 0.106 \\
400 & 0.190 & 10000 & 0.092 & 400 & 0.228 & 10000 & 0.136
\end{tabular}

The result of the work upon the molecular conductivity of cadmium iodide in acetone shows a close analogy to the case of lithium nitrate.

1) Wied. Ann. 64, 655 (1898).

2) Jahresber. Schles. Ges. f. vaterländ. Kultur, 1606, Naturw. Sekt., 1-9. 
There is almost no change in molecular conductivity with dilution, until a concentration of 0.0002 normal is reached. From this point the increase is quite rapid, but it has not been found possible to reach the maximum molecular conductivity, though this point has been, we beliere, closely approached. The Ostwald constant, calculated for these solutions, shows a very rapid decrease until $\boldsymbol{V}=5000$, where it is constant until $V=50000$. From this point it increases quite rapidly. The large initial value of $K$, with its subsequent decrease, is probably due to association of the salt. The later rise in the value of $K$ is, no doubt, due to the fact that dissociation is not complete at $V=400000$, so that we hare used too small a value for $\mu_{\infty}$ in the calculation of the dissociation at greater concentrations.

Table 19.

Ionization constant for cadmium iodide in acetone. At $0^{\circ}$

\begin{tabular}{rccc:cccc}
$V$ & $K \times 10^{3}$ & $V$ & $K \times 10^{3}$ & $V$ & $K \times 10^{8}$ & \multicolumn{1}{c}{$\boldsymbol{V}$} & $K \times 10^{3}$ \\
10 & 1.6 & 2500 & 0.007 & 10 & 0.834 & 2500 & 0.005 \\
50 & 0.33 & 5000 & 0.005 & 50 & 0.164 & 5000 & 0.003 \\
100 & 0.16 & 10000 & $\mathbf{0 . 0 0 5}$ & 100 & 0.078 & 10000 & 0.004 \\
200 & 0.08 & 30000 & 0.004 & 200 & 0.042 & 30000 & 0.004 \\
400 & 0.041 & 50000 & 0.005 & 400 & 0.021 & 50000 & 0.005 \\
800 & 0.012 & 100000 & 0.028 & 800 & 0.011 & 100000 & 0.014 \\
1600 & 0.012 & 200000 & 0.062 & 1600 & 0.006 & 200000 & 0.108
\end{tabular}

It is thus erident that in acetone the dissociation is not complete at either temperature, although it is more nearly so at $0^{\circ}$ than at $25^{\circ}$. This is to be expected from a knowledge of the temperature coefficient, which is negatire below a dilution of 10000 liters, and has a very small positire value at higher dilutions. Since the change in conductivity, corresponding to a given rise in temperature, is the resultant of two factors, which are probably opposite in their effect; i. e., decrease in viscosity and probable decrease in ionization, it is seen that there nust be a very large decrease in the ionization of cadmiun iodide in acetone as we pass from $0^{0}$ to $25^{\circ}$. Thus, the molecular conductivity curve for cadmium iodide in acetone-water mixtures at $0^{\circ}$ suggests the fluidity curre for the solrents, more plainly than at $25^{\circ}$, and it seems probable that, could the conductirity be accurately measured at dilutions as high as 600000 or 700000 liters, the curves of molecular conductivity would become similar to those of fluidity, so that molecular conductivity and viscosity would be inversely proportional, as is the case with lithium nitrate and most other electrolytes. There is no means of knowing 
what the numerical ralue of the product of viscosity and conductivity would be. Taking the highest conductivity that was obtained in each case, the product is irregular, as is seen in table 20 .

Table 20.

\begin{tabular}{|c|c|c|c|c|c|c|}
\hline \multirow[t]{2}{*}{${ }_{0}^{\circ}$ Acetone } & \multicolumn{5}{|c|}{$\eta \cdot \mu_{v}$ for cadmium iodide in mixed solvents. } & $\eta \cdot \mu_{v}$ \\
\hline & \multicolumn{6}{|c|}{ In acetone and methyl alcohol. } \\
\hline 0 & 63 & 0.0086 & 0.54 & 63 & 0.0058 & 0.36 \\
\hline 25 & 94 & 0.0073 & 0.69 & 105 & 0.0052 & 0.54 \\
\hline 50 & 39 & 0.0060 & 0.23 & 43 & 0.0043 & 0.19 \\
\hline 75 & 32 & 0.0017 & 0.15 & 29 & 0.0037 & 0.11 \\
\hline 100 & 100 & 0.0043 & 0.43 & 118 & 0.0035 & 0.41 \\
\hline \multicolumn{7}{|c|}{ In acetone and ethyl alcohol. } \\
\hline 0 & 14 & 0.0210 & 0.29 & 42 & 0.0118 & 0.50 \\
\hline 25 & 22 & 0.0113 & 0.25 & 43 & 0.0073 & 0.31 \\
\hline 50 & 44 & 0.0073 & 0.32 & 58 & 0.0051 & 0.30 \\
\hline 75 & 76 & 0.0052 & 0.40 & 96 & 0.0040 & 0.38 \\
\hline 100 & 100 & 0.0043 & 0.43 & 118 & 0.0035 & 0.41 \\
\hline \multicolumn{7}{|c|}{ In acetone and water. } \\
\hline 0 & 155 & 0.0178 & 2.76 & 279 & 0.0089 & 2.48 \\
\hline 25 & 81 & 0.0291 & $2 \cdot 36$ & 171 & 0.0125 & $2 \cdot 14$ \\
\hline 50 & 67 & 0.0301 & 2.02 & 144 & 0.0131 & 1.89 \\
\hline 75 & 71 & 0.0166 & 1.18 & 134 & 0.0088 & 1.18 \\
\hline 100 & 100 & 0.0043 & 0.43 & 118 & 0.0035 & 0.41 \\
\hline
\end{tabular}

The irregularity in the value of the product of maximum conductivity and viscosity, in the case of acetone and methyl alcohol mixtures is probably due to the fact that complete dissociation was more nearly approached in some cases than in others. The values for pure acetone and for pure methyl alcohol are, howerer, nearly the same, and we may expect that the curves for maximum molecular conductivity, when finally obtained, will be found to be nearly straight lines, similar to the fluidity curves for the solvents.

In the acetone and ethyl alcohol mixtures there is a fair degree of constancy in the product, and the conductivity curre is nearly the theoretical one. The acetone and water curve is also nearly the same as the fluidity curve for the solvents, and the value of the product almost exactly follows the rule of mixtures; although here again the exceptionally high value of the product for water is noticed, it being about 2.5 instead of 1.0 , as in the case of lithium nitrate and tetraethylammonium iodide. The reason for this interesting fact must, for the present, remain unexplained. 
Conductivity and viscosity of dilute solutions of lithium nitrate, etc. 417

The results obtained by Jones for the molecular weight of cadmium iodide in acetone are given in table 21 , and are shown graphically in figure 16. The formula weight is 364 , while the molecular weight found in a 0.09 normal solution in acetone is 448 . Considerable polymerization is thus indicated.

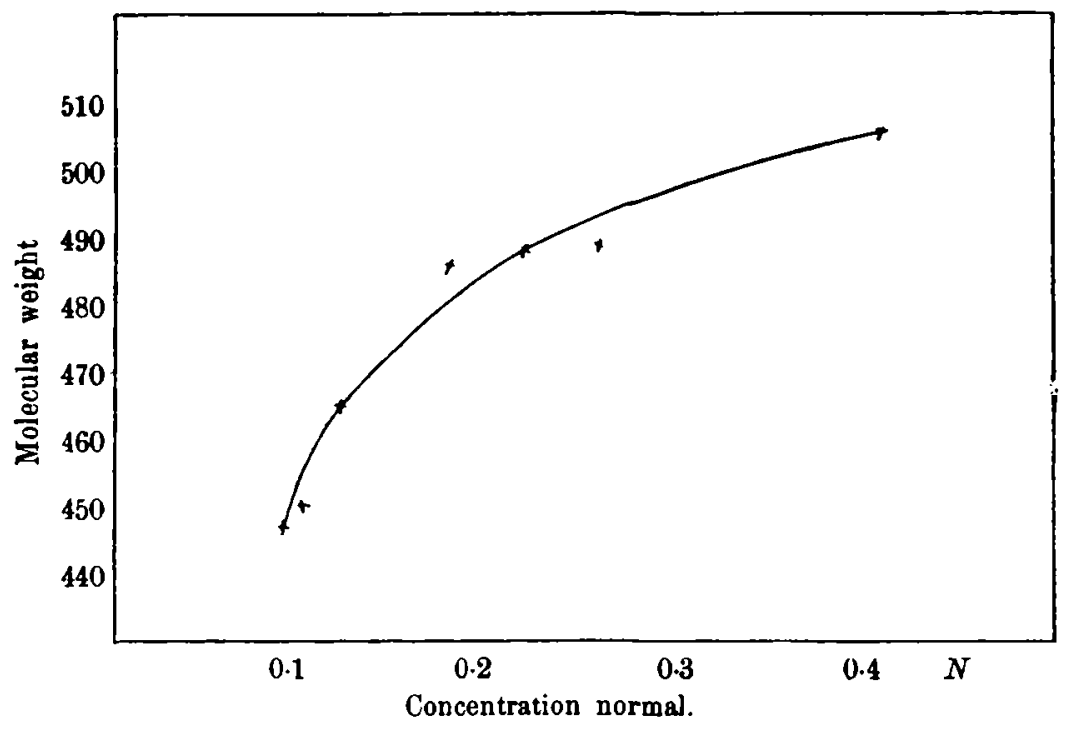

Fig. 16. Molecular weight of cadmium iodide in acetone.

Table 21.

Molecular weight of cadnium iodide in acetone.

$\begin{array}{ccccc}\begin{array}{c}\text { Acetone } \\ \text { grams }\end{array} & \begin{array}{c}C d I_{3} \\ \text { grams }\end{array} & \begin{array}{c}\text { Conc. } \\ \text { normal }\end{array} & \begin{array}{c}\text { B. P. Rise } \\ \text { degrees }\end{array} & \begin{array}{c}\text { Molecular } \\ \text { weight }\end{array} \\ \mathbf{5 5 . 1 6} & 1.7789 & 0.09 & 0.124 & \mathbf{4 4 8 . 6} \\ 56.03 & 2.0540 & 0.10 & 0.140 & \mathbf{4 5 1 . 7} \\ \mathbf{5 7 . 5 1} & \mathbf{2 . 4 9 5 1} & \mathbf{0 . 1 2} & 0.160 & \mathbf{4 6 7 . 8} \\ 56.37 & 3.7790 & 0.18 & 0.236 & \mathbf{4 9 0 . 1} \\ \mathbf{5 5 . 9 2} & \mathbf{4 . 5 0 2 0} & 0.22 & 0.282 & \mathbf{4 9 2 . 4} \\ 57.28 & \mathbf{5 . 4 0 0 0} & \mathbf{0 . 2 6} & 0.330 & \mathbf{4 9 2 . 9} \\ \mathbf{5 7 . 2 8} & 8.5460 & 0.41 & 0.504 & \mathbf{5 1 0 . 7}\end{array}$

\section{Summary.}

The work of others has shown that the general law which correlates conductivity and viscosity fails in the case of lithium nitrate, lithium bromide, cobalt chloride, and calcium nitrate, when dissolved in mixtures containing acetone as one of the components of a binary solvent mixture. 
418 Harry C. Jones and Edward G. Manin, Conductivity and viscosity, etc.

This is made evident by the abnormally low values for conductivity of these substances in acetone, and it was thought that it might be due to association of the salt in acetone. Determination of conductivity at high dilutions has shown that lithium nitrate, when completely dissociated, is no exception to the rule that molecular conductivity varies inversely as the viscosity; and boiling-point measurements have shown that, at ordinary concentrations, the salt is associated in acetone to a considerable extent.

Cadmium iodide had already been shown to be associated in acetone, and further work on its conductivity in mixed solvents has shown that its behavior is similar to that of lithium nitrate.

The temperature coefficients of conductivity of lithium nitrate are of about the same order of magnitude as the temperature coefficients of fluidity, though generally somewhat smaller, except at high dilutions. This might be expected from the fact that dissociation is less at $25^{\circ}$ than at $0^{\circ}$. This influence of temperature is seen more clearly in acetone solutions of cadmium iodide, which have negative temperature coefficients of conductivity below a dilution of 0.0001 normal.

Similar investigations are in progress, having to do with solutions of the other salts mentioned above.

Physical Chemical Laboratory, Johns Hopkins University. Baltimore, May 1908. 